GASTRO-OESOPHAGEAL REFLUX DISEASE

\title{
Endoscopic gastroplication for the treatment of gastro- oesophageal reflux disease: a randomised, sham-controlled trial
}

\author{
M P Schwartz, H Wellink, H G Gooszen, J M Conchillo, M Samsom, A J P M Smout
}

Gut 2007;56:20-28. doi: 10.1136/gut.2006.096842

See end of article for authors' affiliations

Correspondence to: Dr M P Schwartz,

Department of

Gastroenterology, University Medical Centre, PO Box 85500, 3508 GA Utrecht,

The Netherlands; m.p. schwartz@umcutrecht.nl

Revised 29 May 2006

Accepted 31 May 2006

Published Online First

8 June 2006 al reflux disease (GORD) is rapidly emerging, but Background: Endoscopic treatment for gastro-oesophageal reflux disease (GORL
there is a great need for randomised controlled trials to evaluate the efficacy.

Design and setting: A single-centre, double-blind, randomised, sham-controlled trial of endoscopic gastroplication by the Endocinch suturing system.

Patients and interventions: 60 patients with GORD were randomly assigned to three endoscopic gastroplications $(n=20)$, a sham procedure $(n=20)$ or observation $(n=20)$. The research nurse and patients in the active and sham groups were blinded to the procedure assignment. After 3 months, open-label active treatment was offered to all patients.

Outcome measures: The primary outcome measures were proton pump inhibitor (PPI) use and GORD symptoms, and secondary measures were quality of life, 24-h oesophageal acid exposure, oesophageal manometry and adverse events. Follow-up assessments were performed at 3, 6 and 12 months.

Results: At 3 months, the percentage of patients who had reduced drug use by $\geqslant 50 \%$ was greater in the active treatment group $(65 \%)$ than in the sham $(25 \%)$ or observation groups $(0 \%)(p<0.02)$. Symptoms (heartburn and to a lesser extent regurgitation) improved more in the active group than in the sham group. Three Short Form-20 quality of life subscales (role function, general health and bodily pain perception) improved in the active group versus sham. Oesophageal acid exposure was modestly decreased after active treatment $(p<0.02)$, but not significantly greater than after the sham procedure $(p=0.61)$. The active treatment effects on PPI use, symptoms and quality of life persisted after 6 and 12 months of open-label follow-up $(n=41)$, but $29 \%$ of patients were retreated in this period. No serious adverse events occurred. Conclusions: Endoscopic gastroplication, using the Endocinch device, reduced acid-inhibitory drug use, improved GORD symptoms and improved the quality of life at 3 months compared with a sham procedure. The effects persisted up to 12 months. However, the reduction in oesophageal acid exposure was not greater after endoscopic treatment than after a sham procedure.
G astro-oesophageal reflux disease (GORD) is a common and chronic disorder with a considerable impact on a patient's quality of life and healthcare utilisation resources. ${ }^{1-5}$ Medical and surgical treatment methods available to date are often sufficient but also cumbersome and expensive. Proton pump inhibitors (PPIs) are a safe and effective treatment for GORD, ${ }^{6}$ but many patients are not willing to accept a lifelong use of drugs. Patients who experience persistent symptoms despite daily drug use can be offered a laparoscopic fundoplication, which has proved to be safe and efficacious, ${ }^{7}$ but in a significant subset of these patients new symptoms arise postoperatively (eg, dysphagia and bloating). ${ }^{89}$ For these reasons, a minimally invasive endoscopic antireflux treatment could be an appealing alternative approach.

Recently, three endoscopic antireflux techniques have been developed: radiofrequency energy, copolymer injection and suturing. ${ }^{10}$ A common goal of these different therapeutic approaches is to improve the antireflux barrier function of the oesophagogastric junction (OGJ). Endoluminal treatments are designed to be carried out in an outpatient setting. Only a few investigators have studied the effectiveness of these types of treatment in a randomised sham-controlled fashion. Corley et $a l^{11}$ showed that radiofrequency energy delivered to the OGJ improved GORD symptoms and quality of life when compared with a sham procedure. However, there was no reduction in oesophageal acid exposure or drug use at 6 months. Devière et $a l^{12}$ conducted a randomised, sham-controlled, multicentre trial on the effectiveness of non-resorbable copolymer implantation (Enteryx (Boston Scientific Corporation, Natick, MA, USA)). Active treatment reduced GORD symptoms and PPI use, but again no significant effect on oesophageal acid exposure was found.

The endoscopic antireflux procedure used in the present study is endoluminal suturing with the Bard endoscopic suturing system (Endocinch (Bard Endoscopic Technologies, CR Bard, Billerica, MA, USA)) developed by Swain and Mills, ${ }^{13}$ which it is one of the most used endoscopic antireflux devices worldwide. The aim of endoscopic suturing is to place gastroplications at or just below the OGJ to reduce the frequency and volume of reflux of gastric contents into the oesophagus. The important advantages of this technique are its reversibility and titratability. Numerous authors have reported on the safety and feasibility of the procedure. ${ }^{14-17}$ Several openlabel studies have shown promising short-term and mediumterm results, ${ }^{14-16}$ but there is a need for a randomised comparative trial to show its efficacy over placebo. The objective of this research was to evaluate the therapeutic efficacy of endoscopic gastroplication in GORD compared with the sham procedure.

Abbreviations: ANOVA, analysis of variance; GORD, gastrooesophageal reflux disease; IQR, interquartile range; LOS, lower oesophageal sphincter; OGJ, oesophagogastric junction; PPI, proton pump inhibitor; SF-20, Short Form-20 


\section{PATIENTS AND METHODS}

We conducted a single-centre, randomised, double-blind trial of endoscopic gastroplication for the treatment of GORD, comparing three groups: active gastroplication, sham gastroplication and no treatment (observation). The study was approved by the medical ethics committee of the University Medical Centre Utrecht, Utrecht, The Netherlands.

\section{Patients}

Patients with typical persistent symptoms of GORD (heartburn or regurgitation) were recruited from the outpatient clinic of the Department of Gastroenterology at the University Medical Centre Utrecht (Utrecht, The Netherlands) and by an advertisement in a local newspaper.

All patients were at least partially responsive to PPI drugs and had been dependent on PPIs for at least 1 year. They were considered for non-medical treatment because of their unwillingness to take drugs lifelong, because of inadequate responsiveness to medical treatment, or because they experienced side effects due to drugs. Patients were included only when oesophageal $\mathrm{pH}$ results were compatible with the diagnosis of GORD - that is, oesophageal $\mathrm{pH}<4>5 \%$ of the time or a symptom association probability $>95 \% .{ }^{18}$ Patients $<18$ years of age, with severe oesophageal motility disorder on manometry, hiatus hernia $>3 \mathrm{~cm}$ in length, a history of thoracic or gastric surgery, reflux oesophagitis grade C or D (LA classification), Barrett's epithelium, other severe comorbidities (including cardiopulmonary disease, portal hypertension, collagen diseases, morbid obesity and coagulation disorders), use of anticoagulant or immunosuppressive drugs, or a history of alcohol or drug misuse were excluded.

\section{Patient assessment at baseline}

To assess eligibility, patients underwent an upper endoscopy if not already performed in the past 2 years. Baseline values of the daily dose of PPI needed to achieve optimal symptom control were recorded for each patient during a run-in period of 1 month. During the last week of this period, patients discontinued acid-suppressive drugs and underwent stationary oesophageal manometry and 24-h ambulatory $\mathrm{pH}$ monitoring if not already performed in the past year. Questionnaires on GORD symptoms and quality of life assessments before treatment were also completed off medication.

\section{Randomisation}

After having obtained written informed consent, patients were randomly allocated to one of three groups: active treatment, sham treatment or no treatment (observation). The observation group was added to enable assessment of the magnitude of placebo effect of the sham procedure. Treatment status was assigned by using block randomisation. For each patient, a numbered envelope was drawn from a set of sealed envelopes containing the allocation on a card. The assignment was recorded in a computer database by an independent staff member. Shortly before each intervention the endoscopist was informed about the patient's group assignment. Subsequent contact between the patient and the endoscopist was minimised. Patients randomised to active or sham treatment were blinded with regard to their assignments. A research nurse, blinded to the treatment assignments, contacted the patients and carried out subsequent outcome assessments.

\section{Intervention}

Endoscopic suturing was carried out to create a preset number of three gastroplications in all patients in the active treatment group. All procedures, both active and sham, were carried out by one and the same endoscopist (MPS). As described previously, ${ }^{14}$ the procedure was carried out using two video gastroscopes (type Olympus GIF-160 (Olympus Nederland BV, Zeeterwoude, The Netherlands)) and the endoscopic suturing device (Endocinch). After endoscopic placement of an oesophageal overtube, two stitches were placed adjacent to one other, using the same thread. The first gastroplication was positioned about $1.5-2 \mathrm{~cm}$ below the squamocolumnar line along the lesser curvature. The second endoscope was used to create the gastroplication by tightly pulling the sutures together and placing a suture anchor. A second gastroplication was placed $1 \mathrm{~cm}$ above the first, and a third gastroplication was placed at the level of the second along the greater curvature.

The sham procedure was carried out using the same equipment, but without the suturing needle and thread loaded. The endoscopist and two trained nurses carried out the same treatment routine as during active treatment for a duration of 40 min, including placement of an overtube, but no mucosal tissue was grasped or stitched. All procedures were carried out under deep sedation, with a combination of midazolam and pethidine administered intravenously. Oxygen saturation was monitored continuously during the procedure. After the procedure, patients were observed for a period of $4 \mathrm{~h}$ in the outpatient clinic. Blood pressure and heart rate were measured hourly. Before their departure, patients were seen by the research nurse, who was blinded to the type of treatment, to obtain general information on the recording and reporting of adverse events, the use of drugs and food intake. Patients assigned to the observation group received no interventional treatment.

\section{Objectives}

The hypotheses tested in this study were that active treatment would:

1. decrease the use of antisecretory drug;

2. decrease GORD symptoms;

3. improve quality of life; and

4. reduce oesophageal acid exposure.

\section{Follow-up}

Patients in the active and sham treatment groups were instructed to discontinue PPI drugs from day 5 after having undergone treatment. Patients in the observation group were off drugs as they had undergone $\mathrm{pH}$ monitoring. If symptoms returned, PPI treatment (maintenance or on demand) was restarted without consulting a doctor. Patients were free to increase or reduce the daily PPI dose as desired, depending on their GORD symptoms. Use of other antacids was discouraged. Drug use was recorded daily. One month after treatment, the research nurse contacted each patient by telephone to enquire about PPI consumption, present symptoms and the occurrence of adverse events (ie, sore throat, dysphagia, retrosternal pain and nausea).

After 3 months, GORD symptoms and quality of life questionnaires were completed, l week off drugs in all groups, and oesophageal manometry and ambulatory 24-h pH monitoring were repeated in the active and sham groups. Subsequently, patients were unblinded with regard to the treatment they had received. The number of patients responding to treatment was assessed, response being defined as a $\geqslant 50 \%$ reduction in the use of PPIs. Patients from the sham and observation groups were offered open-label active treatment. In case of treatment failure in the active treatment group the patient was offered a repeat endoscopic treatment, consisting of the addition of one or more gastroplications. Follow-up was continued for up to 12 months after the gastroplication procedure. 


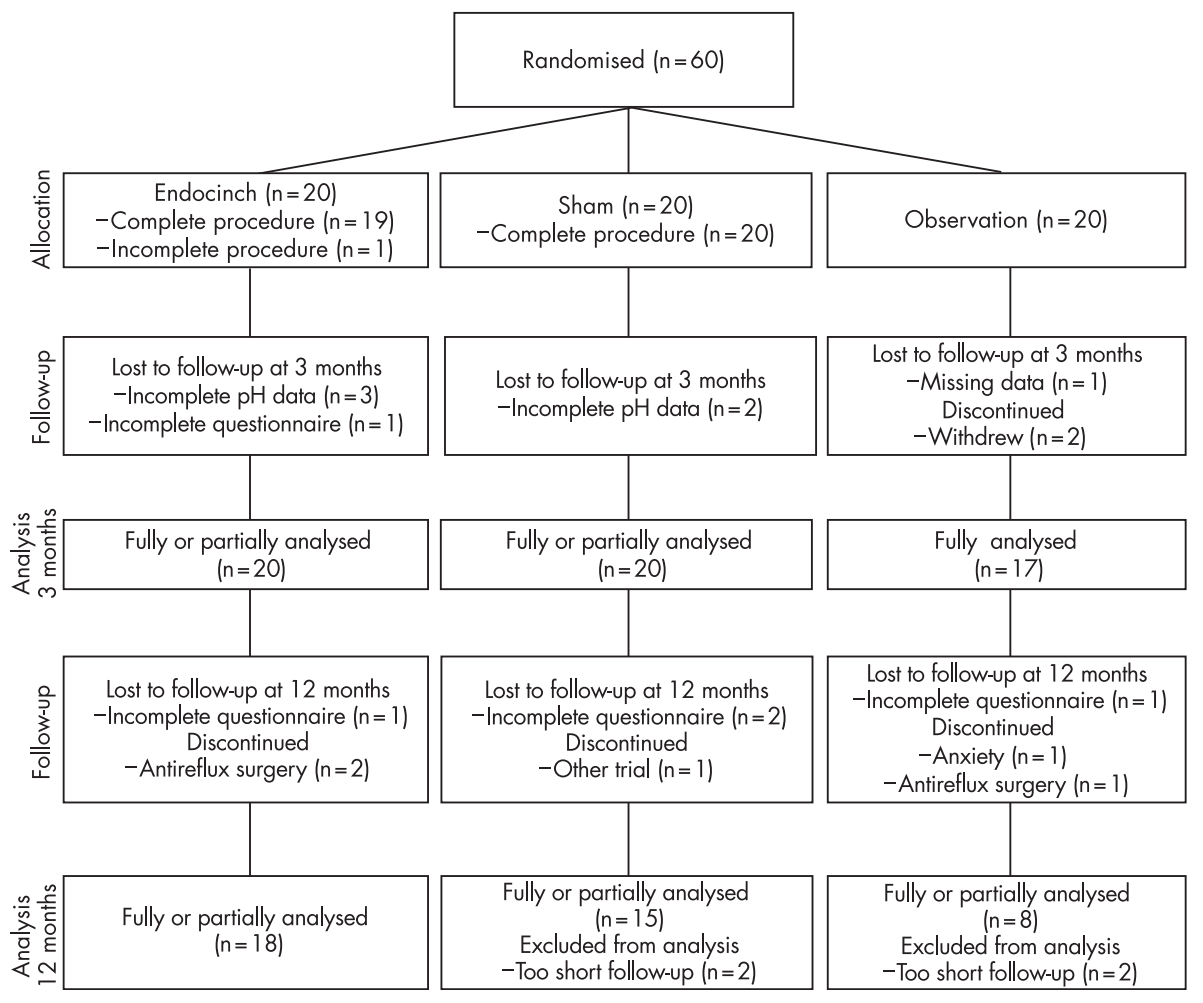

Figure 1 Flow diagram of trial.

\section{Outcome measures}

The primary end point at 1, 3, 6 and 12 months was the use of antisecretory drugs (daily PPI dose) and those at 3, 6 and 12 months were the symptom scores for heartburn and regurgitation. Symptoms were scored according to a 6-point scale measuring frequency ( $>5$ times daily, 2-5 times daily, once daily, once weekly, once monthly or $<1$ monthly) and a 4point scale measuring severity (not, mildly, moderately and very severe). ${ }^{8}$ GORD symptom scores were calculated by multiplying frequency and severity scores.

Secondary end points at 3 and 12 months were quality of life scores, and those at 3 months were oesophageal acid exposure characteristics (using 24-h pH monitoring) and lower oesophageal sphincter (LOS) pressure. The occurrence of adverse events was assessed at 1 month. Quality of life assessments were carried out using the 20-item Short-Form Health Survey (SF20), which comprises six dimensions of quality of life: physical function, role function, social function, mental health, general health and bodily pain perception. After transformation of each individual scale to a 100-point scale, 0 represents the worst score and 100 the best. In bodily pain perception, however, a higher score is negative: the patient encounters more pain.

\section{Oesophageal manometry and ambulatory $\mathrm{pH}$ monitoring}

Manometry was carried out using a water-perfused catheter with a sleeve sensor (Dentsleeve, Mui Scientific, Ontario, Canada) connected to a pneumohydraulic perfusion pump. The catheter was passed transnasally into the stomach and the sleeve sensor was positioned at the central point of the lower oesophageal sphincter. Intraluminal oesophageal pressures were recorded at 5, 10 and $15 \mathrm{~cm}$ above the upper margin of the LOS. The manometric response to 10 standardised wet swallows was recorded. The residual pressure of the LOS during relaxations in response to wet swallows was measured. For $\mathrm{pH}$ monitoring, a pH glass electrode catheter was introduced into the oesophagus and positioned $5 \mathrm{~cm}$ above the upper margin of the LOS, determined during manometry. Data were stored in a digital data logger, using a sampling rate of $0.2 \mathrm{~Hz}$. The intraoesophageal $\mathrm{pH}$ was measured for $24 \mathrm{~h}$. Manometry and $\mathrm{pH}$ data were interpreted by independent (blinded) staff members.

\section{Sample size}

Power calculations before the study were aimed to detect the primary outcomes. Calculations were based on uncontrolled data gathered from previous studies. ${ }^{14}{ }^{16}$ It was estimated that 54 patients had to be included $(\alpha=0.05, \beta=0.20)$, assuming that $70 \%$ in the treatment group, $20 \%$ in the placebo group and $0 \%$ in the observation group would respond (ie, $\geqslant 50 \%$ improvement compared with baseline values). Six additional patients were enrolled to allow for dropouts.

\section{Statistical analysis}

Analyses were performed according to the intention-to-treat principle. Data are presented as mean (standard deviation (SD)) for normally distributed data and as median (interquartile range (IQR)) for non-normally distributed data.

Intraindividual differences between baseline and post-treatment values were analysed with the paired Student's t test for normally distributed data or the Wilcoxon signed-ranks test for non-normally distributed data. Differences between the three groups were analysed with a one-way ANOVA (analysis of variance) for normally distributed data or a Kruskal-Wallis test for non-normally distributed data. If significant differences were found, multiple comparisons were made with Bonferroni correction. Comparisons involving only two groups (ie, openlabel follow-up and analysis of the $\mathrm{pH}$ and manometry data) were analysed using the unpaired Student's t test. Logistic regression analysis was used to explore the relationship between two variables (eg, the occurrence of adverse events and treatment outcome, or the change in oesophageal acid 
exposure and treatment response). Differences were considered significant when $\mathrm{p}<0.05$.

\section{RESULTS}

Sixty patients were enrolled between August 2003 and May 2005 (fig 1). All patients were randomly assigned without deviations from the randomisation protocol. Random variation resulted in patients undergoing sham treatment having slightly higher baseline quality of life score in the SF-20 subscale general health. No other significant differences were observed in baseline data between the three groups (table 1).

In three patients from the observation group, no follow-up data were available: two patients withdrew from the trial before the 3-month evaluation and in one patient data were missing. One patient (randomised to active treatment) did not use PPIs but a H2-receptor antagonist; data on this patient were included when analysing drug use (use related to baseline values), with the exception of calculating the mean dose ( $\mathrm{mg}$ ) of PPIs. Partial or complete 3-month data were available for 57 patients.

\section{Treatment}

In one patient of the active treatment group, only two of the planned three gastroplications were placed, due to technical problems. The other 39 patients assigned to active or sham treatment underwent a technically successful and uneventful treatment procedure. Thus, 56 patients received the intended treatment ( $\mathrm{n}=19$, active; $\mathrm{n}=20$, sham; $\mathrm{n}=17$, observation), but 57 were analysed according to the intention-to-treat principle. Patients in the active group $(n=20)$ were sedated with a mean dose of 14 (4) mg midazolam and 46 (11) mg pethidine. The mean procedure time, from start of endoscopy to removal of the endoscope, was 43 (11) min. In the sham group $(\mathrm{n}=20), 12$ (4) mg midazolam and 45 (10) mg pethidine was administered.

\section{Crossover and retreatment}

After 3 months, 30 patients from the sham and observation groups crossed over to active treatment (fig 1). The remaining seven patients from these groups received an alternative endoscopic or surgical treatment for GORD. Thus, a total of 50 patients received active treatment, of whom 41 were analysed after 1-year, open-label follow-up.

Within a year, $12(29 \%)$ patients were retreated with a mean of $1.4(0.5)$ extra plications, after a median period of 4.0 (3.255.0 ) months. In these patients $72 \%$ of sutures were still present, but only $19 \%$ were judged as functional.

\section{Primary end points \\ Drug use}

At 1 and 3 months, there was a significantly greater reduction in daily PPI use in active patients compared with sham patients (fig 2). When sham was compared with observation, PPI use was reduced in the sham group as well. At 3 months, 13 (65\%) patients in the active group responded to intervention ( $\geqslant 50 \%$ reduction in PPI use) compared with $5(25 \%)$ patients in the sham group and none $(0 \%)$ in the observation group $(p=0.011$, active $v$ sham; $\mathrm{p}=0.05$, sham $v$ observation). In all, there were $8(40 \%)$ patients in the active group and $1(5 \%)$ patient in the sham group who had reduced PPI use by $\geqslant 95 \%$ at 3 months $(p=0.02)$. The reduction of PPI use in the active treatment persisted at 6 and 12 months (fig 2), although an increase in drug use was noted over time $(\mathrm{p}=0.48)$. At 6 months, the use of PPI reduced by $\geqslant 50 \%$ in 32 of 41 (78\%) patients, and by $\geqslant 95 \%$ in $14(34 \%)$ patients. At 12 months, $\geqslant 50 \%$ and $\geqslant 95 \%$ reductions were achieved in $68 \%$ and $29 \%$ of the patients, respectively.

After 1 year, the number of treatment failures was 25 of 45 (56\%) patients (Kaplan-Meier analysis; fig 3).

\section{Symptoms}

Heartburn frequency and scores decreased significantly after active treatment compared with sham treatment at 3 months (table 2, fig 4).

The number of patients that were heartburn-free (frequency $<\mathrm{l} /$ month) was $8(40 \%)$ in the active group, $1(5 \%)$ in the sham group and none in the observation group $(p=0.02$, active $v$ sham). Regurgitation was also reduced after active treatment,

\begin{tabular}{|c|c|c|c|}
\hline Characteristic & $\begin{array}{l}\text { Endocinch group* } \\
(n=20)\end{array}$ & $\begin{array}{l}\text { Sham group* } \\
(n=20)\end{array}$ & $\begin{array}{l}\text { Observation group* } \\
(n=20)\end{array}$ \\
\hline Age (years) & $45(12)$ & $47(12)$ & $47(11)$ \\
\hline Male sex, n (\%) & $12(60)$ & $13(65)$ & $11(55)$ \\
\hline Body mass index $\left(\mathrm{kg} / \mathrm{m}^{2}\right)$ & $27(4)$ & $26(3)$ & $27(4)$ \\
\hline \multicolumn{4}{|l|}{ GORD symptom score $\dagger$} \\
\hline Heartburn & $17.2(4.3)$ & $15.6(6.1)$ & $17.4(4.9)$ \\
\hline Regurgitation & $16.1(4.3)$ & $14.6(5.7)$ & $14.9(5.6)$ \\
\hline \multicolumn{4}{|l|}{ SF-20 scoreł } \\
\hline Physical function & $39(35)$ & $49(29)$ & $44(35)$ \\
\hline Role function & $62(36)$ & $85(27)$ & $68(37)$ \\
\hline Social function & $63(38)$ & $85(21)$ & $67(33)$ \\
\hline Mental health & $75(18)$ & $75(16)$ & $66(21)$ \\
\hline General health & $37(26)$ & $55(20)$ & $34(26)$ \\
\hline Bodily pain perception & $72(26)$ & $66(28)$ & $69(30)$ \\
\hline PPI dose, $\mathrm{mg} \S$ & $40(20-80)$ & $40(20-40)$ & $40(33-59)$ \\
\hline Time $\mathrm{pH}<4$, \% & $10.2(5.6)$ & $9.5(5.2)$ & $9.6(4.7)$ \\
\hline LOS pressure, $\mathrm{kPa}$ & $1.1(0.9)$ & $1.1(0.8)$ & $0.8(0.6)$ \\
\hline Hiatal hernia length, cm & $1.8(0.7)$ & $1.4(1.1)$ & $1.8(1.4)$ \\
\hline Oesophagitis grade A/B, n (\%) & $8(40)$ & $9(45)$ & $8(40)$ \\
\hline
\end{tabular}

*Data are presented as mean (SD) or median (IQR), except when indicated otherwise. tFrequency $\times$ severity (range $0-24$ ), off antisecretory drugs.

¥Short-Form General Health Survey (higher scores for better function, except for bodily pain perception; range 0-100), off antisecretory drugs.

§Proton pump inhibitor dose per day, except 1 patient using $\mathrm{H} 2$-receptor antagonist. Off antisecretory drugs. 


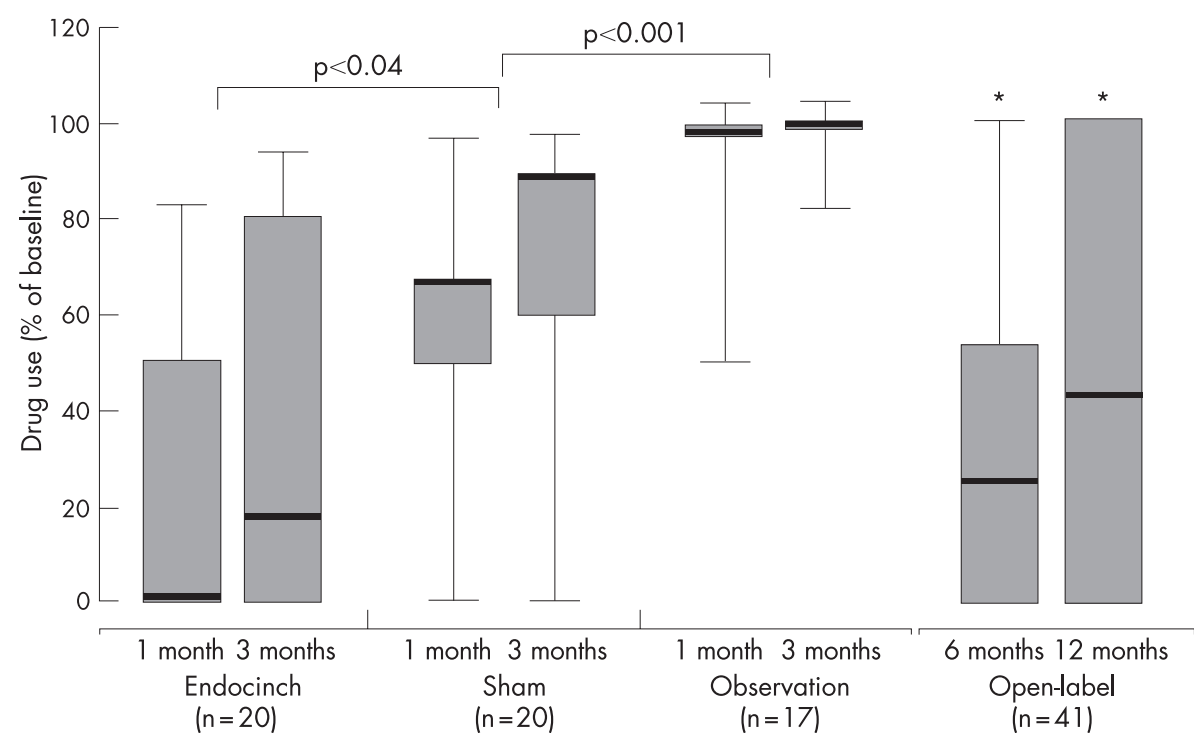

Figure 2 Drug use, expressed as percentage of the baseline dose of antisecretory drugs. The horizontal lines of the boxes denote the 25th, 50th (median) and 75 th centile values. Error bars denote the 0 and 100th centiles. $p$ Values apply to between-group comparisons at 1 and 3 months. ${ }^{*} p<0.001$, compared with baseline.

although to a lesser extent, and was significant only for regurgitation frequency when compared with sham (table 2). Heartburn severity and scores slightly improved after observation at 3 months, but there were no significant differences between sham and observation. Symptom improvements were sustained during open-label follow-up (table 3), with 15 of 37 $(41 \%)$ patients reporting no heartburn at 12 months.

\section{Secondary end points}

\section{Quality of life}

Three months after active treatment, SF-20 quality of life scores were significantly improved in three subscales (role function, general health and bodily pain perception) compared with sham (table 2). No differences were observed in SF-20 scores between sham and observation at 3 months. After 6 and

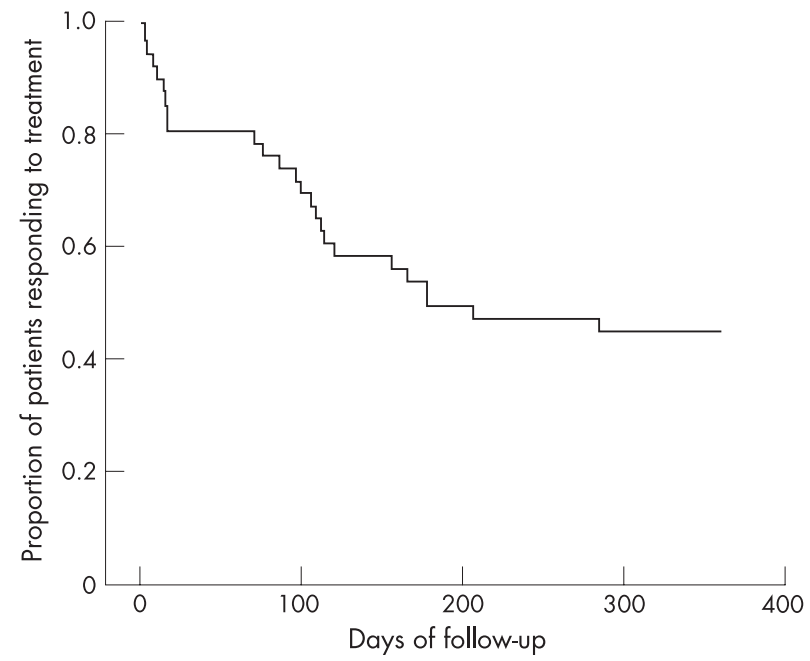

Figure 3 Kaplan-Meier analysis of proportion of patients $(n=45)$ responding to active treatment during 1-year follow-up. Treatment failures also included patients who chose to receive retreatment $(n=12)$ or an alternative antireflux treatment $(n=4)$, according to intention-to-treat analysis.
12 months, the improvements in quality of life scores persisted (table 3).

\section{Oesophageal acid exposure}

At 3 months after the procedure, mean oesophageal acid exposure times were decreased in both the active group and, to a slightly lesser extent, the sham group $(p=0.02$, active; $\mathrm{p}=0.10$, sham; table 4).

No differences were seen between the two groups. Figure 5 shows the individual oesophageal acid exposure times. Acid exposure times normalised ( $\mathrm{pH}<4$ during $<5 \%$ of time) in 5 of $17(29 \%)$ evaluated patients of the active group and in 4 of 18 $(22 \%)$ patients of the sham group $(\mathrm{p}=0.71)$. Acid exposure times were reduced in 12 of $17(71 \%)$ evaluated patients after active treatment and in 11 of $18(61 \%)$ patients after the sham procedure $(p=0.73)$. No significant changes were found in numbers of reflux periods.

\section{Oesophageal manometry}

No differences were seen in lower oesophageal sphincter pressure (table 4) or oesophageal body contractions (data not shown) when comparing the two treatment groups.

\section{Adverse events}

No major adverse events requiring clinical observation, blood transfusion or administration of drugs other than paracetamol (table 5) were seen.

All adverse events were mild and transient, resolving spontaneously within 1 week. Adverse events occurred more frequently in the active group, with the exception of experiencing a sore throat. One patient developed a subcutaneous haematoma as result of a misplaced intravenous line.

\section{Subgroup analysis}

Subgroup analysis was done to explore whether a response to treatment $(\geqslant 50 \%$ reduction in PPI use) was related to a decreased oesophageal acid exposure. A comparison of responders $(\mathrm{n}=13$, with $12 \mathrm{pH}$ studies) versus non-responders $(\mathrm{n}=7$, with $5 \mathrm{pH}$ studies) showed that there was a greater decrease in nightly acid exposure $(-4.9 \% \vee 3.3 \% ; \mathrm{p}=0.036)$ in responders, 


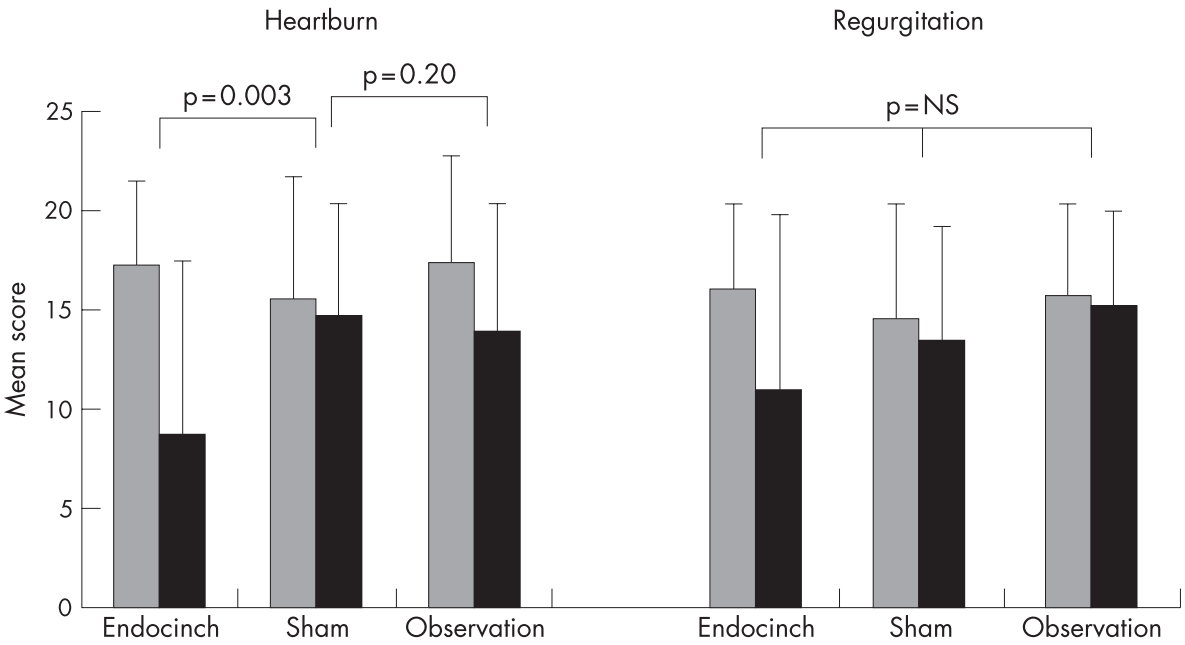

Figure 4 Heartburn and regurgitation scores (frequency $\times$ severity) before (grey bars) and after 3 months of follow-up (black bars). Data are means (SD). Statistical tests compared mean differences in absolute change from baseline values between groups, and, if significant, multiple comparisons were carried out.

although there was no significant difference in total acid exposure time $(-3.6 \% v-0.5 \% ; \mathrm{p}=0.24)$.

To explore whether the occurrence of an adverse event was related to the outcome of treatment, logistic regression analysis of responders versus non-responders was carried out. Patients experiencing dysphagia after the procedure (transient; $\mathrm{n}=10$ ) were more likely to respond to treatment (odds ratio (OR), 13.5; $95 \%$ confidence interval (CI), 1.2 to $152.2 ; \mathrm{p}=0.035)$. In the group experiencing dysphagia $(\mathrm{n}=10$, nine $\mathrm{pH}$ studies $)$ mean $\%$ acid exposure time after the procedure was reduced more compared with the group not experiencing dysphagia $(\mathrm{n}=10$, eight $\mathrm{pH}$ studies; $-4.9 \% v-0.2 \%, \mathrm{p}=0.022$ ).

\section{DISCUSSION}

This randomised trial showed that endoscopic gastroplication, using the Endocinch procedure, significantly reduced GORD symptoms, reduced the use of PPI drugs, and improved quality of life scores at 3 months compared with the sham procedure. The symptom heartburn was improved more than the symptom regurgitation. Oesophageal acid exposure, however, was not reduced more after active treatment than after the sham procedure.

The results of this sham-controlled trial confirm those of prior open-label studies showing that, in the short and intermediate term, endoscopic gastroplication improves GORD symptoms and quality of life, and reduces the use of acidinhibitory drugs. ${ }^{14-16}{ }^{19-21}$ However, the extent of the effect was less in this study than in open-label studies, with just $29 \%$ of patients of this study managing to stop use of drugs completely, compared with $50-70 \%$ at 3 months in open-label studies. ${ }^{16-21}$ Furthermore, the improvement in oesophageal acid exposure was not significantly greater than after sham treatment, emphasising the importance of a sham comparison.

All three main types of endoscopic GORD treatments (radiofrequency energy, injection and suturing) have now been evaluated by a randomised sham comparison. ${ }^{11}{ }^{12}$ Interestingly, in all these three trials symptoms improved significantly as a result of endoscopic treatment, whereas oesophageal acid exposure failed to improve compared with the sham procedure. Although within-group comparisons showed a lower acid

Table 2 Treatment effects at 3 months

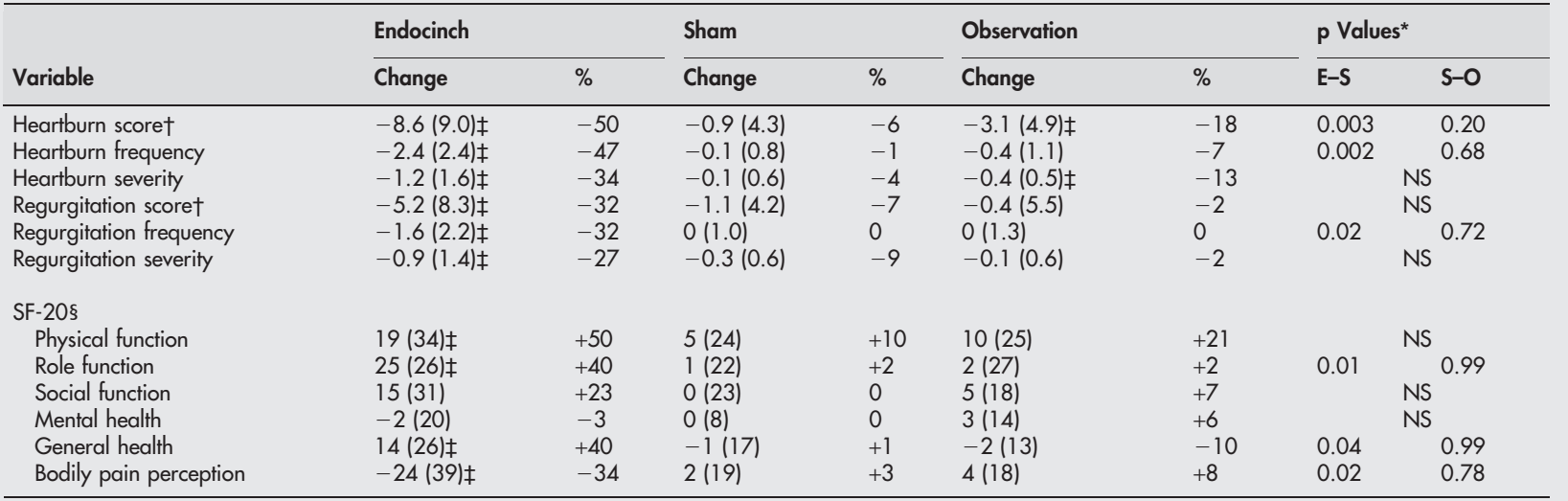

NS, not significant.

*Statistical tests analysed differences between the three groups, and, if significant, compared the Endocinch group with the sham group (E-S) and the sham group with the observation group (S-O)

†Frequency $\times$ severity (range $0-24)$, off antisecretory drugs.

$\neq \mathrm{p}<0.05$, within-group comparisons.

§Short-Form General Health Survey (higher scores for better function, except for bodily pain perception; range 0-100), off antisecretory drugs. 
Table 3 Treatment effects at 6 and 12 months open-label follow-up

\begin{tabular}{|c|c|c|c|c|c|c|c|}
\hline \multirow[b]{2}{*}{ Variable } & \multirow[b]{2}{*}{ Baseline } & \multicolumn{2}{|l|}{6 Months } & \multicolumn{2}{|l|}{12 Months } & \multicolumn{2}{|c|}{ p Values* } \\
\hline & & Absolute values & $\% \dagger$ & Absolute values & $\% \dagger$ & B-6 & B-12 \\
\hline $\begin{array}{l}\text { Heartburn score } \neq \\
\text { Heartburn frequency } \\
\text { Heartburn severity } \\
\text { Regurgitation score } \neq \\
\text { Regurgitation frequency } \\
\text { Regurgitation severity }\end{array}$ & $\begin{array}{l}16(6) \\
4.9(1.4) \\
3.1(1) \\
15.1(5.1) \\
4.9(1.1) \\
3(0.8)\end{array}$ & $\begin{array}{l}8.3(8.6) \\
2.7(2.3) \\
2(1.5) \\
8.2(7.7) \\
2.9(2.3) \\
1.9(1.3)\end{array}$ & $\begin{array}{l}-48 \\
-45 \\
-35 \\
-46 \\
-41 \\
-37\end{array}$ & $\begin{array}{l}7.5(7.7) \\
2.6(2.3) \\
1.7(1.5) \\
8.4(8.4) \\
3(2.6) \\
1.7(1.5)\end{array}$ & $\begin{array}{l}-53 \\
-47 \\
-45 \\
-44 \\
-39 \\
-43\end{array}$ & $\begin{array}{l}<0.001 \\
<0.001 \\
<0.001 \\
<0.001 \\
<0.001 \\
<0.001\end{array}$ & $\begin{array}{l}<0.001 \\
<0.001 \\
<0.001 \\
<0.001 \\
<0.001 \\
<0.001\end{array}$ \\
\hline $\begin{array}{l}\text { SF-20§ } \\
\text { Physical health } \\
\text { Role function } \\
\text { Social function } \\
\text { Mental health } \\
\text { General health } \\
\text { Bodily pain perception }\end{array}$ & $\begin{array}{l}49(35) \\
63(47) \\
72(33) \\
76(17) \\
46(25) \\
64(31)\end{array}$ & $\begin{array}{l}\text { NA } \\
\text { NA } \\
\text { NA } \\
\text { NA } \\
\text { NA } \\
\text { NA }\end{array}$ & & $\begin{array}{l}66(37) \\
78(40) \\
77(32) \\
76(17) \\
56(29) \\
40(36)\end{array}$ & $\begin{array}{l}+35 \\
+24 \\
+7 \\
+0 \\
+22 \\
-38\end{array}$ & & $\begin{array}{l}<0.001 \\
0.03 \\
\text { NS } \\
\text { NS } \\
<0.001 \\
<0.001\end{array}$ \\
\hline
\end{tabular}

NA, not assessed; NS, not significant; SF-20.

*Statistical comparisons between baseline and 6 months (B-6), and between baseline and 12 months (B-12).

†Percentage of change compared with baseline.

fFrequency $\times$ severity (range 0-24), off antisecretory drugs.

§Short-Form General Health Survey (higher scores for better function, except for bodily pain perception; range 0-100), off antisecretory drugs

exposure after active treatment in the present study, betweengroup differences were far from significant, as even the sham group improved.

This discrepancy between improvement of GORD symptoms (and drug use) and a lack of improvement in oesophageal acid exposure raises various questions. Firstly, how does endoscopic gastroplication for GORD actually work? Is it merely the reduction in oesophageal acid exposure or does it alter reflux characteristics, such as the proximal extent of reflux in the oesophagus and the volume of the refluxate? Our study was not designed to answer these questions, but we included a subgroup analysis to compare responders with non-responders to further explore the role of oesophageal acid exposure. The definition of a responder ( $\geqslant 50 \%$ reduction in PPI use) used is somewhat arbitrary but consistent with definitions used by other authors. ${ }^{12}{ }^{17}$ The result, showing that responders had a greater reduction in acid exposure than non-responders, suggests that at least part of the effect of active treatment is due to a reduction in oesophageal acid exposure. However, the proportion of the decrease in acid exposure might well be a more important factor in symptomatic response than the absolute decrease in oesophageal acid exposure. We know from PPI studies that up to $50 \%$ of patients with GORD continue to have an abnormal oesophageal $\mathrm{pH}$ profile, despite complete symptom control on drugs. ${ }^{22}$ A reduction in the proximal extent of the refluxate or specific effects on different types of reflux episodes (acidic, weakly acidic, alkaline and gas-liquid composition) might also play a part. These issues can be dealt with by studies using intraluminal impedance monitoring. Another possible explanation for the treatment effect includes a decreased oesophageal visceroperception as a result of endoscopic gastroplication, as was recently shown in a small study. ${ }^{23}$

Thus, the pathogenesis of GORD is complex, and thereby the interpretation of oesophageal $\mathrm{pH}$ studies. In this respect, how can the improvement in oesophageal acid exposure after a sham procedure be explained? A possible explanation is that there is a difference in patient attitude during the $\mathrm{pH}$ study after the procedure compared with the baseline $\mathrm{pH}$ measurement. Most patients experience a 24-h ambulatory $\mathrm{pH}$ study off drugs as a bothersome investigation; in fact, more than the treatment procedure itself. For this reason, many participants will be less motivated to undergo a second measurement than the first, which would result in an attitude and behaviour leading to avoidance of activities associated with acid reflux during the second $\mathrm{pH}$ study. This "postprocedure motivation bias" is likely to occur in both the sham and the active treatment groups. If such a bias indeed has a role, the improvement of oesophageal $\mathrm{pH}$ after endoscopic treatment does not properly reflect the true effect of treatment. The net positive effect of endoscopic treatment on acid exposure will be even less pronounced than the data shown now. This type of bias could have played a part in all previously reported uncontrolled studies on endotherapy for GORD that included $\mathrm{pH}$ data.

Table 4 Treatment effects for $\mathrm{pH}$ metry and manometry at 3 months

\begin{tabular}{|c|c|c|c|c|c|}
\hline & \multicolumn{2}{|c|}{ Endocinch group $(n=17)$} & \multicolumn{2}{|l|}{ Sham group $(n=18)$} & \multirow[b]{2}{*}{ p Valuet } \\
\hline & Absolute change* & $\%$ & Absolute change* & $\%$ & \\
\hline $\begin{array}{l}\text { Acid upright } \\
\text { Acid supine } \\
\text { Acid total } \ddagger \\
\text { Number of reflux periods } \\
\text { LOS pressure (kPa) }\end{array}$ & $\begin{array}{l}-2.5(6.1) \\
-2.5(8.2) \\
-2.7(4.4) \S \\
-13(28) \\
-0.0(0.7)\end{array}$ & $\begin{array}{l}-22 \\
-35 \\
-29 \\
-19 \\
-1\end{array}$ & $\begin{array}{l}-1.8(6.6) \\
-1.7(5.2) \\
-1.9(4.6) \\
-1(24) \\
-0.3(0.8)\end{array}$ & $\begin{array}{l}-14 \\
-31 \\
-20 \\
-1 \\
-21\end{array}$ & $\begin{array}{l}0.74 \\
0.74 \\
0.61 \\
0.18 \\
0.35\end{array}$ \\
\hline \multicolumn{6}{|c|}{$\begin{array}{l}\text { LOS, lower oesophageal sphincter. } \\
{ }^{*} \text { Mean (SD). } \\
\text { †Statistical tests compared the mean differences in absolute change from baseline values between the Endocinch and } \\
\text { sham groups. } \\
\ddagger \text { Percentage of time oesophageal } \mathrm{pH}<4 \text {, off antisecretory drugs. } \\
\S p=0.02 \text {, within-group comparisons. }\end{array}$} \\
\hline
\end{tabular}




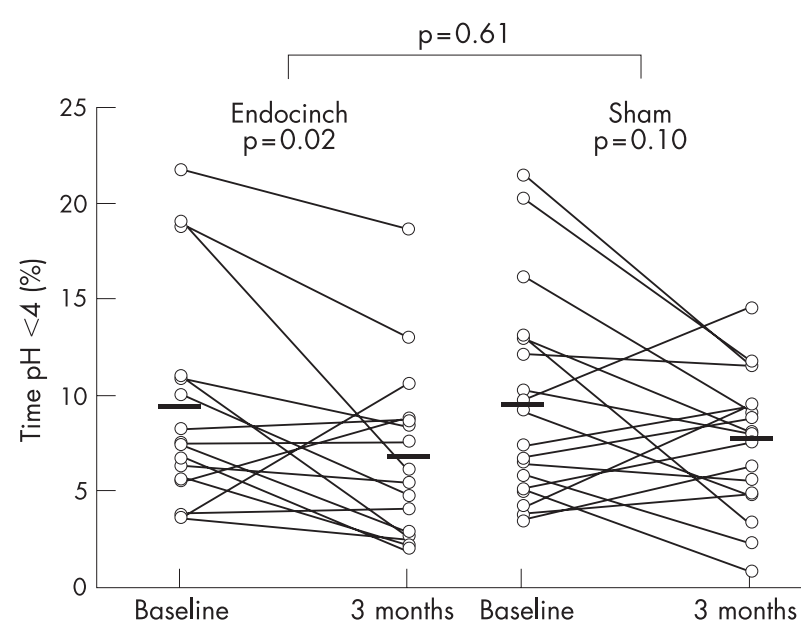

Figure 5 Individual 24-h oesophageal acid exposure values before and 3 months after procedure for the Endocinch and sham groups. Horizontal lines represent mean values.

It should be noted that there was an, albeit relatively small, number of dropouts from postprocedure measurements, most importantly three patients in the active group declining a postprocedure $\mathrm{pH}$ metry. By our definition, two of these patients were non-responders and one a responder, which may have slightly influenced the results in favour of active treatment.

One might argue that patients randomised to the active group were "unblinded" by the side effects they experienced as a result of the gastroplications (ie, dysphagia, local chest pain) and therefore would be biased towards a treatment effect. ${ }^{24}$ Indeed, subgroup analysis showed that this group of patients responded better to active treatment than the group without these side effects. However, their oesophageal acid exposure improved more as well, suggesting a true effect of treatment, not a bias effect. Thus, it seems that the occurrence of side effects, such as dysphagia, is an indication of effectively placed gastroplications and a predictor of success.

For this study, a design that included a third group of patients who received no active or sham treatment but who were followed up during ad libitum use of PPIs was chosen. The reason for including this group was to be able to assess the effect of the sham procedure on GORD symptoms. This threearm design was justified by the fact that the observation group showed a spontaneous improvement in the symptom heartburn at 3 months, which-if present in the sham group-would have been falsely attributed to a sham effect.

A major concern regarding this procedure is its durability in the long term. For this reason we included a 1-year, open-label follow-up, after establishing the primary efficacy in a shamcontrolled 3-month design. Treatment effects were reasonably consistent with the 3-month results, with only a marginal increase of drug use over time. However, we should take into account that $29 \%$ of patients again received treatment with one or two extra gastroplications. Promising long-term results, as published in previous reports, ${ }^{15} 1619$ could therefore be only partly confirmed by the present study. We share concerns with other others with regard to the durability of the endoscopically placed sutures. ${ }^{17} 25$ Many sutures are lost or seem to be already loose at 2 or 3 months after the procedure, ${ }^{17}{ }^{25}$ and a correlation between efficacy and presence of sutures has been established. ${ }^{26}$ Although we did not include a second, postprocedure gastroscopy in our protocol, a large percentage (81\%) of nonfunctional (loose) sutures was seen during retreatment in non-responders. Probably, postprocedure results would have
Table 5 Adverse events

\begin{tabular}{lll}
\hline Variable & $\begin{array}{l}\text { Endocinch treatment } \\
\mathbf{n}(\%)\end{array}$ & $\begin{array}{l}\text { Sham treatment } \\
\mathbf{n}(\%)\end{array}$ \\
\hline Sore throat & $8(40)$ & $9(45)$ \\
Chest soreness & $6(30)$ & $0(0)$ \\
Dysphagia $<7$ days & $10(50)$ & $1(5)$ \\
Belching & $1(5)$ & $0(0)$ \\
Abdominal pain & $1(5)$ & $1(5)$ \\
Bloating & $2(10)$ & 0 \\
Early satiety & $1(5)$ & 0 \\
Hiccups & $1(5)$ & 0 \\
Sedation-related & 0 & $1(5)$ \\
\hline
\end{tabular}

changed in favour of active treatment if all sutures had remained in place, but the present results reflect the current efficacy of this (imperfect) procedure. It is conceivable that placement of more than three sutures in individual patients, for example, those with larger hiatal openings, would improve the results. We chose, however, to adhere to a strict treatment protocol with a relatively high number of plications (ie, three), based on previous open-label results. ${ }^{16}$

In summary, this sham-controlled trial of endoscopic gastroplication for GORD showed that this procedure improves GORD symptoms, quality of life and drug use in about two thirds of the patients up to 12 months. However, the reduction in oesophageal acid exposure is modest and is not greater after active gastroplication than after sham treatment. The results emphasise that caution should be undertaken when interpreting the results of uncontrolled $\mathrm{pH}$ monitoring studies. The presence of transient dysphagia after the procedure seems to predict a favourable treatment outcome. The procedure was safe and could be carried out well in an outpatient setting under conscious sedation. Although this study confirmed that this method represents an attractive alternative treatment option for patients with uncomplicated GORD unwilling to take drugs, the procedure should be improved to increase the effect on oesophageal acid exposure (and probably the proportion of patients responding) and improve the durability of sutures. Widespread use of the endoscopic suturing device should probably be avoided until the technique is improved and efficacy on objective end points has been proved in a shamcontrolled fashion.

\section{ACKNOWLEDGEMENTS}

We thank Elvire Muris and the other nurses who assisted in endoscopic suturing and who have diligently cared for the patients. We acknowledge the statistical support of Dr P Westers, Biostatistics Centre, University of Utrecht, Utrecht, The Netherlands.

\section{Authors' affiliations}

M P Schwartz, H Wellink, J M Conchillo, M Samsom, A J P M Smout, Department of Gastroenterology, University Medical Centre, Utrecht, The Netherlands

H G Gooszen, Department of Surgery, University Medical Centre, Utrecht, The Netherlands

Competing interests: HW was supported by a grant from Janssen-Cilag pharmaceuticals.

\section{REFERENCES}

1 Sandler RS, Everhart JE, Donowitz M, et al. The burden of selected digestive diseases in the United States. Gastroenterology 2002;122:1500-11.

2 Nebel OT, Fornes MF, Castell DO. Symptomatic gastroesophageal reflux: incidence and precipitating factors. Am J Dig Dis 1976;21:953-6.

3 Revicki DA, Wood M, Maton PN, et al. The impact of gastroesophageal reflux disease on health-related quality of life. Am J Med 1998;104:252-8. 
4 Richter JE. Long-term management of gastroesophageal reflux disease and its complications. Am J Gastroenterol 1997;92(Suppl):30S-4S.

5 Locke GR III, Talley NJ, Fett SL, et al. Prevalence and clinical spectrum of gastroesophageal reflux: a population-based study in Olmsted County, Minnesota. Gastroenterology 1997; 112:1448-56.

6 Klinkenberg-Knol EC, Festen HP, Meuwissen SG. Pharmacological management of gastro-oesophageal reflux disease. Drugs 1995;49:695-710.

7 Hinder RA, Perdikis G, Klinger PJ, et al. The surgical option for gastroesophageal reflux disease. Am J Med 1997; 103:144S-8S.

8 Bais JE, Bartelsman JF, Bonjer HJ, et al. Laparoscopic or conventional Nissen fundoplication for gastro-oesophageal reflux disease: randomised clinical trial. The Netherlands Antireflux Surgery Study Group. Lancet 2000;355:170-4.

9 Pessaux P, Arnaud JP, Ghavami B, et al. Morbidity of laparoscopic fundoplication for gastroesophageal reflux: a retrospective study about 1470 patients. Hepatogastroenterology 2002;49:447-50.

10 Arts J, Tack J, Galmiche JP. Endoscopic antireflux procedures. Gut 2004;53:1207-14.

11 Corley DA, Katz P, Wo JM, et al. Improvement of gastroesophageal reflux symptoms after radiofrequency energy: a randomized, sham-controlled trial. Gastroenterology 2003;125:668-76.

12 Devière J, Costamagna G, Neuhaus $\mathrm{H}$, et al. Nonresorbable copolymer implantation for gastroesophageal reflux disease: a randomized sham-controlled multicenter trial. Gastroenterology 2005;128:532-40.

13 Swain CP, Mills TN. An endoscopic sewing machine. Gastrointest Endosc 1986;32:36-8

14 Filipi CJ, Lehman GA, Rothstein RI, et al. Transoral, flexible endoscopic suturing for treatment of GERD: a multicenter trial. Gastrointest Endosc 2001;53:416-22.

15 Chen YK, Raijman I, Ben-Menachem T, et al. Long-term outcomes of endoluminal gastroplication: a U.S. multicenter trial. Gastrointest Endosc 2005;61:659-67.
16 Mahmood Z, McMahon BP, Arfin Q, et al. Endocinch therapy for gastrooesophageal reflux disease: a one year prospective follow up. Gut 2003:52:34-9.

17 Schiefke I, Zabel-Langhennig A, Neumann S, et al. Long term failure of endoscopic gastroplication (EndoCinch). Gut 2005;54:752-8

18 Weusten BL, Roelofs JM, Akkermans $L M$, et al. The symptom-association probability: an improved method for symptom analysis of 24 -hour esophageal pH data. Gastroenterology 1994; 107:1741-5.

19 Liu JJ, Carr-Locke DL, Lee LS, et al. Endoluminal gastroplication for treatment of patients with classic gastroesophageal reflux symptoms and borderline $24-\mathrm{h} \mathrm{pH}$ studies. Scand J Gastroenterol 2004;39:615-20.

20 Schiefke I, Soeder H, Zabel-Langhennig A, et al. Endoluminal gastroplication: what are the predictors of outcome? Scand J Gastroenterol 2004;39:1296-303.

21 Arts J, Lerut T, Rutgeerts $P$, et al. A one-year follow-up study of endoluminal gastroplication (Endocinch) in GERD patients refractory to proton pump inhibitor therapy. Dig Dis Sci 2005;50:351-6.

22 Milkes D, Gerson LB, Triadafilopoulos G. Complete elimination of reflux symptoms does not guarantee normalization of intraesophageal and intragastric $\mathrm{pH}$ in patients with gastroesophageal reflux disease (GERD). Am J Gastroenterol 2004:99:991-6.

23 Wenzel G, Kuhlbusch R, Heise J, et al. Relief of reflux symptoms after endoscopic gastroplication may be associated with reduced esophageal acid sensitivity: a pilot study. Endoscopy 2005;37:236-9.

24 Shaheen NJ. Raising the bar in studies of endoscopic anti-reflux procedures. Gastroenterology 2005; 128:779-82.

25 Abou-Rebyeh H, Hoepffner N, Rosch T, et al. Long-term failure of endoscopic suturing in the treatment of gastroesophageal reflux: a prospective follow-up study. Endoscopy 2005:37:213-16.

26 Ben-Menachem T, Goel S, Zonca M, et al. Endoscopic surveillance of plications after endoluminal gastroplication (ELPG) for GERD. Gastrointest Endosc 2003;57:AB128.

\section{EDITOR'S QUIZ}

\section{Answer \\ From question on page 12}

Horrileno et al coined the term juvenile polyp in 1957 to describe a distinctive childhood colorectal polyp. Juvenile polyps are non-neoplastic hamartomatous epithelial polyps with little or no malignant potential. They usually affect children $<10$ years of age who present with bloody stools. These polyps are generally located in the colon, predominantly in the rectosigmoid colon. It is rare to find a solitary juvenile polyp outside the colon, except as part of the uncommon juvenile polyposis syndrome. Only three cases of juvenile polyp in the small intestine have been reported previously in the literature. Juvenile polyp is also an infrequent cause of gastrointestinal bleeding or intussusception in adults. Less than $10 \%$ of cases are diagnosed after the age of 60 years. To the best of our knowledge, this is the only adult case report of juvenile polyp in the small intestine.

The management of a juvenile polyp usually includes endoscopic resection to prevent further bleeding. Surgery is required in cases of intussusceptions. Although polypectomy has been used successfully to remove small intestinal polyps during double-balloon enteroscopy, this patient underwent surgical resection because the nature of the polyp was uncertain, despite endoscopic biopsy and the hypervascular nature of the polyp revealed by the computed tomography scan. The patient recovered smoothly from the surgery and experienced no more bleeding during the following 6 months.

doi: 10.1136/gut.2006.094631 